\title{
SHEET METAL FORGING PROCESS FOR THIN-WALLED STRUCTURES WITH CROSSED RIBS: PROCESS DESIGN, SIMULATION AND A FORMING EXPERIMENT
}

\author{
1,2Bin FENG, ${ }^{1,2}$ Ji HE, 1,2Shuhui LI, ${ }^{1,2}$ Bin GU, 1,2Zhongqin LIN \\ ${ }^{1}$ State Key Laboratory of Mechanical System and Vibration, Shanghai Jiao Tong University, Shanghai, \\ China, msv@situ.edu.cn \\ ${ }^{2}$ Shanghai Key Laboratory of Digital Manufacture for Thin-walled Structures, Shanghai Jiao Tong University, \\ Shanghai, China, bmtc@situ.edu.cn
}

https://doi.org/10.37904/metal.2021.4112

\begin{abstract}
A sheet-forging process is proposed to form thin-walled structures with crossed-ribs. To solve the problem of grid distortion in finite element simulations, an element reconfiguration strategy that combines a stress-strain map solution and element reconstruction is applied, and typical samples with crossed-ribs are designed to verify the accuracy of simulation. Through the compression tests, the true stress-strain curves are achieved under different strain rates. By applying the FE method, the flow behavior of the materials is investigated, and the non-linear relationship between reduction amount and rib height is obtained. According to the plastic deformation behaviors, more uniform deformation in the later forming period leads to more material flowing into the rib grooves.
\end{abstract}

Keywords: Sheet-forging process, crossed-ribs, plastic deformation behavior, element reconfiguration strategy, average grain size

\section{INTRODUCTION}

As the capability requirements of aerospace equipment increase, large-scale stiffened and thin-walled structures are widely employed on rockets and aircrafts for the purpose of reducing weight to improve flight distance while still maintaining the structure strength and stiffness. These complex structures have high-profile ribs and comparatively thin walls, which are difficult to machine. Sheet-forging technology has been proposed to manufacture these complex thin-walled structures. The sheet-forging process is designed to fabricate sheet material; it combines a forging method with sheet metal forming, and forging can well control the thickness and shape of the target structure [1,2]. This paper describes a sheet-forging process to produce thin-walled structures with complex ribs, which are widely used in aerospace.

Until now, several plastic forming technologies have been used to form ribbed components, such as isothermal local loading forming [3,4], isothermal extrusion forming [5,6], and flow spinning [7,8]. Compared with precision casting technology, plastic forming technology can significantly increase the strength and toughness of components and improve the mechanical properties.

In sheet-forging technology, a general sheet metal forming method is combined with a bulk metal forming process to form complex features out of sheet plane with bulk forming operations. Wang and Yoshikawa [1] proposed a new hot plate forging technique to produce a cup-like component, and by using finite element simulation and press forming tests, the process features have been investigated and verified. Schneider and Merklein [9] combined deep drawing with upsetting process to form tooth-like parts and proposed a FE model to analyze the forming history of the pre-drawn blank. Hua and Han [10] established a 3D FE model of cold rotary forging process which combines incremental metal forming with cold forging process by the Abaqus software, and the effects of processing parameters of cold rotary forging have been explored. Until now, using 
sheet-forging technology to produce thin-walled structures with complex ribs has rarely been reported, and a large ratio of rib height to sheet thickness is difficult to achieve via conventional forming methods.

In this paper, a new sheet-forging process is designed to integrally form thin-walled structures with more complex ribs, such as orthogonal ribs, oblique intersecting ribs and other various ribbed patterns. A sheetforging device is also proposed in this paper. Evaluating this new forming process is the primary goal of this work, and establishing a 2D elastic-plastic finite element model of this sheet-forging process is the secondary goal. The accuracy of the simulation method is verified via experiments involving forming crossed-rib features.

\section{DESIGN OF SHEET-FORGING EXPERIMENT}

One typical component with crossed-rib features is designed for the sheet-forging process, and this simple part contains only one orthogonal-rib feature, as seen in Figure 1a. In the experiments, to avoid the problem of detaching the finished forging workpieces from the conventional die, the entire die is divided into several parts (see Figure 1b). The dimensions of the original sheet are $50 \times 50 \times 7 \mathrm{~mm}$ : the target width and height of ribs are set to be $3 \mathrm{~mm}$ and $10 \mathrm{~mm}$, and the radius of fillet is set to be $1.5 \mathrm{~mm}$. However, in this experiment, the height of rib is not limited to $10 \mathrm{~mm}$ because we want to find the final forming limit of the height within the ultimate load range of the equipment. The experiments are carried out on a Komatsu servo press machine, and the maximum loading force is $300 \mathrm{t}$. The material used in the experiments is pure lead. The sheet-forging process of typical feature is carried out at room temperature, and oil production butter is used as lubricant during the experiment. Figure 1c shows the formed sample. It is obvious seen that the height of the deformed rib is not uniform; rather, it is higher in the middle region and lower on both sides. However, in the crossed-rib area, the height is relatively uniform. One reason for this difference in height is that the outermost materials of the workpiece have a greater tendency to extend along the in-plane direction than flow into the grooves in the out-of-plane direction. Another reason is that during the forming process, the material undergoes compression condition in the thickness direction and tension condition in the in-plane direction, so the formed ribs also extend along the in-plane direction. Due to gradients in the flow speed of material along the in-plane direction, which is larger in the outmost region and smaller but relatively uniform in the crossed-rib area, the height distribution of ribs shows a large gradient on all sides and is relatively uniform in the middle area.
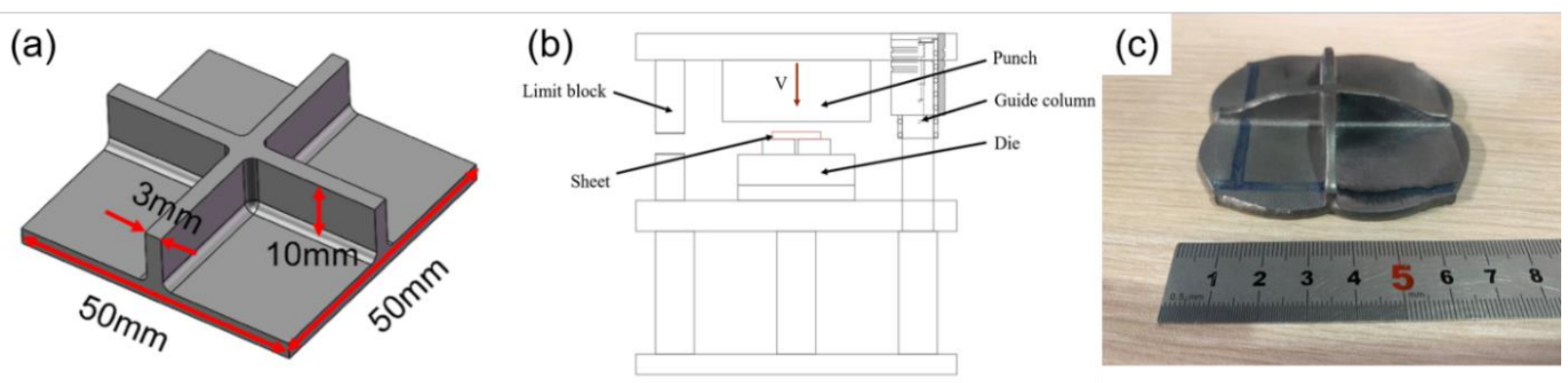

Figure 1 Producing of crossed-ribs: (a) Typical crossed-rib feature, (b) schematic diagrams of the forging die, (c) deformed sample after the forming process

\section{MATERIAL AND CHARACTERIZATIONS}

\subsection{Material}

The material in this work is sampled from a $7.0 \mathrm{~mm}$ thick lead sheet, and the workpiece material is $99.994 \%$ pure lead; it is chosen as a representative model material that can be deformed at room temperature and does not need large forming force. Cleaver and Allwood [11] have recently reported that the response of pure lead is similar to that of hot aluminum because the recrystallization of lead happens at room temperature, and strain and strain rate hardening also appears. For the purpose of numerical modeling, stress-strain curves were 
obtained through uniaxial compression tests. Moreover, after the uniaxial compression tests, metallographic experiments were carried out to obtain the microstructure of the compressional metal.

\subsection{Uniaxial compression tests}

To explore the plastic behavior of pure lead sheet metal during the sheet-forging process, traditional compression tests and three-dimensional digital image correlation (DIC) with the GOM Aramis 4M System [12] were both carried out by using an Instron universal testing machine. According to the GB Standard (GB/T 7314-2017), the compression test specimens were of initial diameter $7 \mathrm{~mm}$ and height $7 \mathrm{~mm}$, and they were all sampled along the thickness direction of the sheet metal. The samples were tested at four true strain rates: $0.01 / \mathrm{s}, 0.1 / \mathrm{s}, 0.2 \mathrm{~s}$ and $0.4 / \mathrm{s}$. Cleaver and Allwood [13] have recently used a $0.05 \mathrm{~mm}$ thick PTEF sheet as compression testing lubrication between the specimen and the upper and lower die. Before each compression test, the PTEF sheets were all replaced. Christiansen et al. [14] have shown that this method can reduce the coefficient of friction to $\mu=0.01$ in their studies.

The true stress-strain curves of the standard compression tests are shown in Figure 2. The flow curves rise initially, and when the true strain reaches values between 0.2 and 0.5 , they level off. It is easy to find that all the material clearly softens after reaching peak values, and the flow stress reduces by $6.05 \%$ when the strain rate is $0.01 / \mathrm{s}$. Schmidt and Haessner [15] have proved that the recrystallization temperature of pure lead is $-80{ }^{\circ} \mathrm{C}$, so it is likely that the dynamic recrystallization leads to the material softening. Figure 2 shows that the peak true stress value improves with increasing strain rate; this phenomenon verifies that the property of this material is strain rate dependent, and this visco-plasticity is similar to the characteristic of materials at

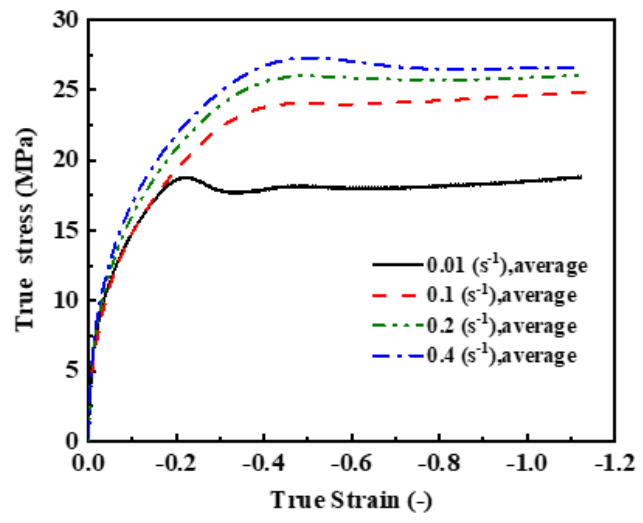

Figure 2 The true stress-strain curves of pure lead under uniaxial compression high temperature.

Since the true stress of pure lead gradually approaches saturation as the strain increases, the Voce equation [16] with the strain rate effect is suited to fit the experimental data. According to the Voce equation, here, the modified type is adopted, and the form of equation can be written as follows:

$\bar{\sigma}=A+B[1-\exp (-m \bar{\varepsilon})]$

where $A, B$, and $m$ are material coefficients, the fitted values of material coefficients are recorded in Table 1. It is obvious that there is an exponential relationship between each material parameter and the strain rate, so the power law $y=K x^{n}$ was adopted to fit the data points; the fitting results are reported in Table 1. According to the results of identifying parameters, the final modified Voce equation expression with considering the influence of strain rate is shown in Equation (2):

$\bar{\sigma}=5.46 \dot{\varepsilon}^{0.078}+24.836 \dot{\varepsilon}^{0.11}\left[1-\exp \left(-5.20 \dot{\varepsilon}^{-0.24} \bar{\varepsilon}\right)\right]$

Table 1 Fitting parameters for Equation (1)

\begin{tabular}{|c|c|c|c|c|c|c|}
\hline \multirow{2}{*}{ Parameters } & \multicolumn{4}{|c|}{$\begin{array}{c}\text { Strain rate } \dot{\varepsilon} \\
(/ \mathbf{s})\end{array}$} & \multirow{2}{*}{$\begin{array}{c}\mathrm{K} \\
(\mathrm{MPa})\end{array}$} & \multirow{2}{*}{$\mathbf{n}$} \\
\hline & 0.01 & 0.1 & 0.2 & 0.4 & & \\
\hline A & 3.76 & 4.67 & 4.83 & 5.01 & 5.46 & 0.078 \\
\hline B & 14.49 & 19.87 & 21.16 & 21.80 & 24.83 & 0.11 \\
\hline $\mathrm{m}$ & 15.94 & 7.13 & 7.63 & 8.09 & 5.20 & -0.24 \\
\hline
\end{tabular}




\section{SIMULATION}

In this study, the sheet-forging process of thin-walled structures with complex ribs is a complicated physical process of multifactor effects, so it is difficult to fully understand the forming mechanism of this new process only via experiments. The finite element method is used to analyze the plastic deformation behavior of proposed process, and the whole procedure is based on the ABAQUS 6.14/Standard environment. To simplify the FE model, we construct a 2D FE model that contains one crossed-rib feature, as shown in Figure 3. In this simulation model, the punch is seen as a discrete rigid body, and the die is also considered as a rigid body; the only deformable part is the pure lead sheet. To simplify the FE model and reduce the calculation time of the simulation, a symmetric simulation strategy is applied. Figure $\mathbf{3}$ shows the cycle of the simulation process: the whole process usually contains many cycles, and they must be continuous. The accuracy of the mapping technology depends on the quality of the mesh reconstructed in ANSA 16.0. Because large strain occurs at the fillets, and the material there is compressed and tensioned seriously, we focus on these areas and often use the same mesh density for the undeformed part to reconstruct the deformed component. Following this principle, we can effectively control the accuracy of the FE method. After remeshing in ANSA, we apply the reconstructed part to build a new FE model in Abaqus and then use Abaqus to output the inp file of this new model. Map solution technology is realized by adding code into this inp file, and then we submit this new job by using the Abaqus command window. If the preset total reduction is achieved, the simulation is completed.

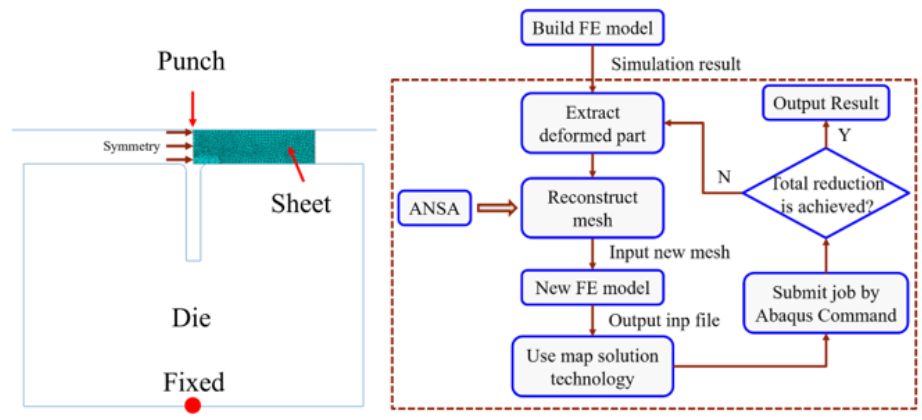

Figure 3 2D FE model of the proposed sheet-forging process and the procedures of the remeshing technology

\section{RESULTS AND DISCUSSION}

The numerical simulation results illustrate that the whole deformation region can be divided into four parts: rounded area, deformed rib area, upper region of the rib and the other compression area. According to the numerical simulation results, the reduction amount has a directly effect on the final height of the deformed rib, and within the maximum load of the equipment, the reduction amount of $3 \mathrm{~mm}$ is applied in the finite element simulation. The whole simulation process is based on the element reconfiguration strategy mentioned in section 4. According to the simulation results and experimental results, Figure 4a shows that simulation results match well with the experimental results, and the height of a single rib can reach $6.2 \mathrm{~mm}$ under a reduction amount of $3 \mathrm{~mm}$. It can be seen from Figure $\mathbf{4 a}$ that the height of the rib is non-linearly increases as the reduction amount increases, and the growth rate of the rib height has a gradually increasing tendency. At the beginning of the process, a reduction amount of $1 \mathrm{~mm}$ can only cause the rib to grow by approximately 1.3 $\mathrm{mm}$, but during the last $0.5 \mathrm{~mm}$ of the forging process, the height of the rib increases by nearly $2 \mathrm{~mm}$, as shown in Figure $\mathbf{4 b}$. According to Figure $\mathbf{4 b}$, the filling mechanism of the material changes with increased reduction amount. In addition, the beginning, a reduction amount of $0.5 \mathrm{~mm}$ can lead to the same amount of rib height. This result means that in this stage, the material undergoes a uniform compression process, and only the material directly above the rib groove flows into the rib groove. However, with increasing reduction amount, the same reduction can cause a higher rib, and the last $0.5 \mathrm{~mm}$ can result in more material flowing into the groove. 

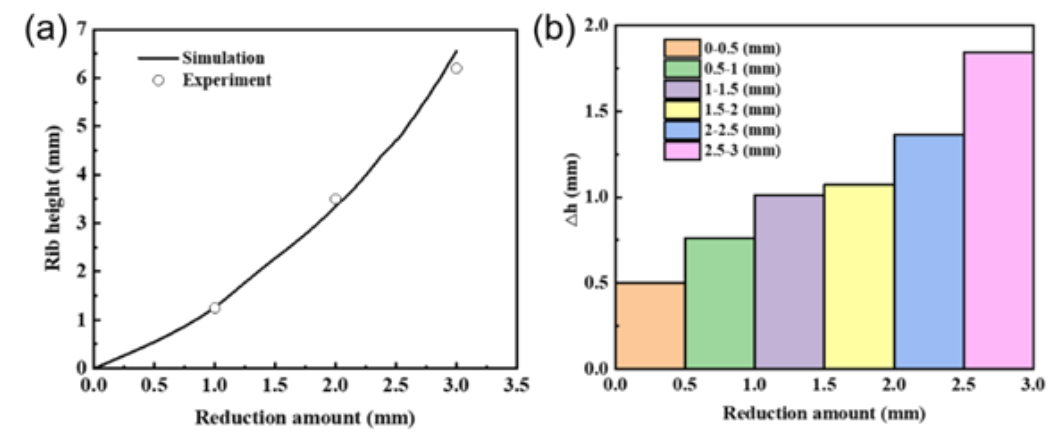

Figure 4 The rib high during deformation: (a) The growth of rib height in the sheet-forging process,

(b) Incremental amount of rib height during the same reduction

To analyze the flow rule in depth, different forming stages are extracted in Figure 5, where Abaqus uses the PEEQ to represent the equivalent plastic strain. An analysis of the simulation results shows that in Figure $5 \mathbf{b}$, the plastic deformation of the material concentrates in the region around the fillet of the rib groove, and shearing deformation also occurs there in the initial forming stage. As the reduction amount increases, the PEEQ of the shearing deformation area also increases, and the shearing region extends from the rounded corners to the upper surface. Moreover, the distribution of PEEQ in shearing deformation area represents the intensity of material flowing along the shear zone. In the last forming stage, the distribution of PEEQ in the shearing deformation zone is rather uniform, which means that the flow of material occurs through the whole thickness of the sheet. Therefore, the rib height increases the most during the last $0.5 \mathrm{~mm}$ reduction of the forming process (see Figure 5f), and this phenomenon is consistent with the experimental results.

(a)

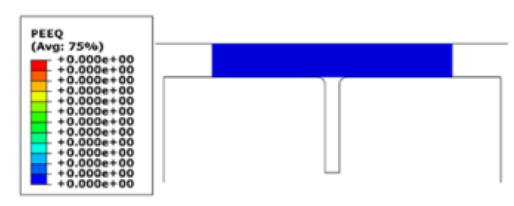

(c) (b)

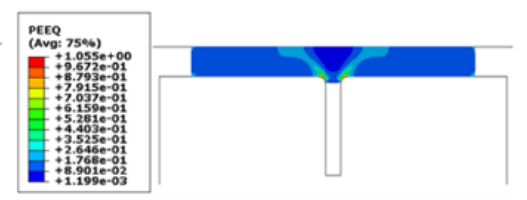

(d)

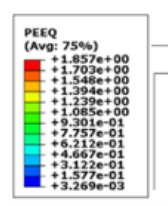

(e)

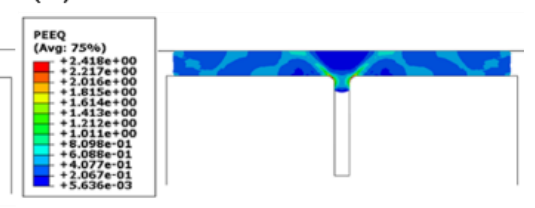

(f)

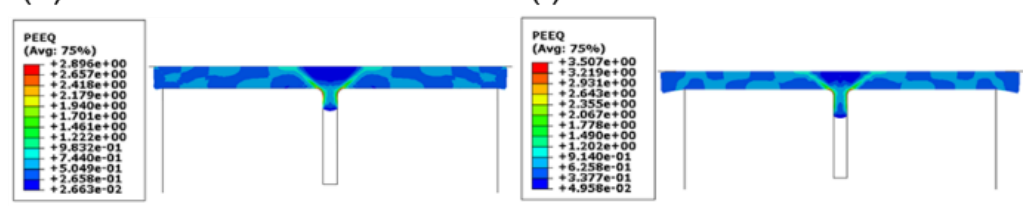

Figure 5 Distribution of equivalent plastic strain under different reduction amounts:

(a) $0 \mathrm{~mm}$, (b) $1 \mathrm{~mm}$, (c) $1.5 \mathrm{~mm}$, (d) $2 \mathrm{~mm}$, (e) $2.5 \mathrm{~mm}$, (f) $3 \mathrm{~mm}$

\section{CONCLUSION}

A new sheet-forging process is proposed to form thin-walled structures with complex ribs, and the plastic deformation behavior is revealed. In order to handle the grid distortion problem during the server plastic deformation process, an element reconfiguration strategy is applied in Abaqus, which combines map solution and element reconstruction methods, where the code of the map solution method is embedded in Abaqus and 
can be called by implicit algorithms, and the simulation results are verified via typical sample forming experiments. From the simulation and experiment results, the rib height increases non-linearly with increasing reduction amount, and the growth of the ratio of the rib height to the sheet thickness is also non-linear. The simulation results show that more uniform deformation in the later forming period leads to more material flowing into the rib grooves.

\section{ACKNOWLEDGEMENTS}

Financial support from the National Natural Science Foundation of China (Grant No.51975364, No.51975366 and No.51790170), and the China Postdoctoral Science Foundation (2021M692036), Fundamental Research Funds for the Central Universities and New Faculty Fund (SMC) of University are gratefully acknowledged.

\section{REFERENCES}

[1] WANG, Z.G., YOSHIKAWA, Y. A new forming method of triple cup by plate forging. Procedia Engineering. 2014, vol. 81, pp. 389-394.

[2] MORAVEC, J. Unconventional Method Of Forming Circumferential Rings On Sheet Metal Parts. In: Metal 2018: 27th International Conference on Metallurgy and Materials. Ostrava: TANGER, 2018, pp. 249-254.

[3] HU, Z.M., BROOKS, J.W., DEAN, T.A. Experimental and theoretical analysis of deformation and microstructural evolution in the hot-die forging of titanium alloy aerofoil sections. Journal of Materials Processing Technology. 1999, vol. 88, no. 1-3, pp. 251-265.

[4] GAO, P.F., YANG, H., FAN, X.G. Quantitative analysis of the material flow in transitional region during isothermal local loading forming of Ti-alloy rib-web component. International Journal of Advanced Manufacturing Technology. 2014, vol. 75, pp. 1339-1347.

[5] YANG, D.Y., PARK, K., KANG, Y.S. Integrated finite element simulation for the hot extrusion of complicated AI alloy profiles. Journal of Materials Processing Technology. 2001, vol. 111, pp. 25-30.

[6] JI, W., ZHOU, Z.H., CAO, H.Q., HAO, A.G., JIANG, X.Q. Research of Isothermal Extrusion Process for Al-alloy Cup-shaped Piece. Casting \& Forging. 2007, vol. 36, pp. 5 (in Chinese).

[7] MA, F., YANG, H., ZHAN, M. Plastic deformation behaviors and their application in power spinning process of conical parts with transverse inner rib. Journal of Materials Processing Technology. 2010, vol. 210, pp. 180-189.

[8] XIA, Q.X., YANG, M.H., HU, Y., CHENG, X.Q. Numerical simulation and experimentation cup-shaped thin-walled inner rectangular gear formed by spinning. Chinese Journal of Mechanical Engineering. 2006, vol. 42, pp. 192196.

[9] SCHNEIDER, T., MERKLEIN, M. Sheet-Bulk Metal Forming of Preformed Sheet Metal Parts. Key Engineering Materials. 2011, vol. 473, pp. 83-90.

[10] HUA, L., HAN, X.H. 3D FE modeling simulation of cold rotary forging of a cylinder workpiece. Materials and Design. 2009, vol. 30, pp. 2133-2142.

[11] CLEAVER, C.J., ALLWOOD, J.M. Incremental profile ring rolling with axial and circumferential constraints. CIRP Annals - Manufacturing Technology. 2017, vol. 1672, pp. 1-4.

[12] LI, S.H., HE, J., GU, B., ZENG, D., XIA, Z.C., ZHAO, Y.X., LIN, Z.Q. Anisotropic fracture of advanced high strength steel sheets: Experiment and theory. International Journal of Plasticity. 2018, vol. 103, pp. 95-118.

[13] CLEAVER, C.J., ALLWOOD, J.M. Curvature development in ring rolling. Journal of Materials Processing Technology. 2019, vol. 267, pp. 316-337.

[14] CHRISTIANSEN, P., MARTINS, P.A.F., BAY, N. Friction compensation in the upsetting of cylindrical test specimens. Experimental Mechanics. 2016, vol. 56, pp. 1271-1279.

[15] SCHMIDT, J., HAESSNER, F. Recovery and recrystallization of high purity lead determined with a low temperature calorimeter. Scripta Metallurgica et Materialia. 1991, vol. 25, no. 4, pp. 969-974.

[16] VOCE, E. The relationship between stress and strain for homogeneous deformation. Journal of the Institute of Metals. 1948, vol. 74, pp. 537-562. 